\title{
La adecuación de la legislación de las Administraciones Públicas andaluzas al marco jurídico de la cooperación transfronteriza*
}

\author{
Francisco Toscano Gil \\ Profesor Contratado Doctor de Derecho Administrativo \\ Universidad Pablo de Olavide de Sevilla
}

SUMARIO: I. PLANTEAMIENTO. II. ANÁLISIS DE LAS LEYES DE LAS ADMINISTRACIONES PÚBLICAS ANDALUZAS DESDE LA PERSPECTIVA DE LA GOOPERAGIÓN TRANSFRONTERIZA. 1. Las leyes de la Administración de la Junta de Andalucía. 2. Las leyes de las Administraciones locales de Andalucía. III. CONGLUSIONES.

\section{RESUMEN:}

El objeto de este trabajo es analizar las leyes de las Administraciones Públicas de Andalucía, con el fin de determinar en qué medida se adecuan al marco jurídico general de la cooperación transfronteriza, y si se contempla en ellas fórmulas específicas de cooperación transfronteriza. Se presta especial atención a instrumentos como los convenios de cooperación, a la creación de organizaciones personificadas, como consorcios, sociedades mercantiles y fundaciones, y a la introducción de una figura nueva en el Derecho andaluz, las llamadas redes de cooperación territorial.

Palabras clave: cooperación territorial; cooperación transfronteriza; legislación administrativa; Administraciones Públicas de Andalucía.

\footnotetext{
* Este trabajo tiene su origen en una comunicación presentada al I Congreso Europeo de Cooperación Territorial Europea y de Vecindad, organizado por el Centro de Estudios Andaluces, en Sevilla el 18 de abril de 2012.
} 


\section{ABSTRACTS:}

The purpose of this paper is to analyze the laws of the Public Administrations of Andalusia, to determine if they are adapted to the juridical general frame of the cross-border cooperation, and if there are contemplated in them specific formulae of cross-border cooperation. Special attention is given to instruments such as cooperation agreements, the creation of personified organizations such as consortia, corporations and foundations, and the introduction of a new figure in the Andalusian law, so-called territorial cooperation networks.

Keywords: territorial cooperation; cross-border cooperation; administrative law; Public Administrations of Andalusia.

\section{PLANTEAMIENTO}

Por todos es sabido, que el ordenamiento jurídico español no atribuye a las Comunidades Autónomas competencias en materia de relaciones internacionales, siendo ésta una cuestión que se reserva en exclusiva al Estado por nuestra Constitución (art. 149.1.3 ${ }^{\circ}$. Si bien, no es menos cierto, que la realidad demuestra que las Comunidades Autónomas, y el resto de entidades territoriales que conforman nuestro Estado descentralizado (Municipios y Provincias), entablan relaciones con entidades públicas de otros Estados. Esta realidad ha sido en gran medida reconocida por nuestro Tribunal Constitucional, que, desde su Sentencia 165/1994, de 26 de mayo, admite que, sin invadir la esfera propia de las relaciones internacionales, las Comunidades Autónomas pueden llevar a cabo actividades con una proyección hacia el exterior, relacionadas con el ejercicio de sus competencias. La acción exterior de las Comunidades Autónomas tiene su límite en el ejercicio del ius contrahendi, en originar obligaciones inmediatas y actuales frente a poderes públicos extranjeros, incidir en la política exterior del Estado, y generar responsabilidad de éste frente a Estados extranjeros u organizaciones inter o supranacionales (F.J. 6 STC 165/1994). Pero, con estas limitaciones, las competencias autonómicas sobre acción exterior son una realidad aceptada por el Tribunal Constitucional ${ }^{1}$, que se ha visto re-

${ }^{1}$ Vid. LÓPEZ GONZÁLEZ, J.I. (2007): "Las relaciones de la Comunidad Autónoma de Andalucía con otros entes públicos", en TEROL BECERRA, M.J. (dir.), La reforma del Estatuto de Autonomía para Andalucía. Las relaciones de la Comunidad Autónoma de Andalucía con otros entes públicos. Pareceres, Instituto Andaluz de Administración Pública, Sevilla, pág. 23. También al respecto, puede verse HOLGADO GONZÁLEZ, M. (2009): "Acción exterior", en TEROL BECERRA, M.J. (dir.), Comentarios al Estatuto de Autonomía para Andalucía, Tirant lo Blanch, Valencia, pág. 647. 
flejada en los distintos Estatutos de Autonomía, especialmente, en las reformas de estos últimos años ${ }^{2}$.

En el ejercicio de sus competencias sobre acción exterior, la Comunidad Autónoma de Andalucía ha venido desarrollando, en los últimos tiempos, importantes y variadas iniciativas, que, no por poco conocidas, deben considerarse, en su trascendencia, de carácter menor ${ }^{3}$. De entre estas iniciativas destacan, por su funcionalidad, las dirigidas a la cooperación territorial con entidades públicas de Estados extranjeros, muy especialmente, aunque no sólo, la cooperación territorial europea, en sus vertientes de cooperación transnacional, cooperación interregional, y cooperación transfronteriza. Y, de entre todas éstas, resulta especialmente interesante la acción pública en cooperación transfronteriza, ya que, por la propia cercanía que implica la idea de encuentro entre fronteras, su utilidad puede ser percibida de forma más directa por el ciudadano.

Para que nos hagamos una idea de lo que estamos diciendo, nada mejor que situarse ante ejemplos concretos. Son, desde luego, significativos muchos de los proyectos de cooperación en los que ha participado Andalucía en el marco del Programa de Cooperación Transfronteriza España-Portugal (20072013), aprobado por la Comisión Europea el 25 de octubre de 2007, y que, en lo que a Andalucía respecta, ha servido para fortalecer sus relaciones con el Alentejo y el Algarve portugués. No hay más que echar un vistazo a los medios de comunicación para darse cuenta de la relevancia de estos proyectos.

Así, en el momento en que se redactan estas líneas, se acaba de inaugurar el cuarto puente internacional entre Portugal y España, construido sobre el río Chanza, y que une la comarca del Andévalo en Huelva con el Bajo Alentejo portugués. Es un claro ejemplo de cooperación transfronteriza, que, al mejorar las comunicaciones, repercutirá, indudablemente, sobre el desarrollo socioeconómico a uno y otro lado de la frontera. En la construcción de este puente, han cooperado, hasta donde sabemos, de un lado, la Consejería de Obras Públicas y Vivienda de la Junta de Andalucía, y la Diputación Provincial de Huelva, y, de otro, la Cámara Municipal de Serpa.

\footnotetext{
${ }^{2}$ De hecho, al hilo del recurso sobre la Ley Orgánica 6/2006, de 19 de julio, de reforma del Estatuto de Autonomía de Cataluña, el Tribunal Constitucional ha tenido ocasión de reiterar esta doctrina, lo que ha hecho en la conocida STC 31/2010, de 28 de junio de 2010 (FF.JJ. 125 y 126)

${ }^{3}$ Puede verse una síntesis de estas actuaciones en TUÑÓN, J. (ed.), IGLESIAS, M., ROLDÁN, J., DANDOY, R. y CARMONA, A. (2011): Gobernanza multinivel: el reto de las regiones mediterráneas. Una perspectiva andaluza, Consejería de la Presidencia, Centro de Estudios Andaluces, Junta de Andalucía, Sevilla, págs. 15 y 16.
} 
Pero también pueden ponerse otros ejemplos recientes, en sectores bien diversos, como el medioambiental, en el que la cooperación transfronteriza a través de una red en la que participan la Consejería de Medio Ambiente de la Junta de Andalucía, el Consejo Superior de Investigaciones Científicas, la Universidad de Huelva y la Administración de la Región Hidrográfica del Algarve, ha facilitado la reintroducción del águila pescadora en los parajes naturales de Marismas del Odiel (Huelva) y la Reserva Natural do Sapal de Castro Marim e Vila Real de Santo António (Portugal). O el desarrollo tecnológico, impulsado desde la Universidad, en concreto, las de Huelva y Algarve, que, con participación, entre otros, de diversas entidades del sector público andaluz y del municipio de Faro, han desarrollado un concurso de ideas para la creación de empresas de base tecnológica, en las que la cooperación transfronteriza se fomenta como factor de competitividad y de promoción del empleo.

Como puede verse, la cooperación transfronteriza aparece como cauce de articulación de intereses bien diversos, con la participación de actores públicos de diferente naturaleza, no sólo la Administración General de la región, sino también sus entidades instrumentales o especializadas, y no sólo la Administración autonómica o regional, sino también las Administraciones locales. A su vez, ésta se articula a través de diferentes mecanismos de relación, que van desde los menos formalizados, como pueden ser la firma de protocolos, acuerdos o convenios de colaboración, la constitución de redes de cooperación, Grupos y Comunidades de Trabajo, a fórmulas más pesadas de organización, como la creación de Consorcios transfronterizos o de Agrupaciones Europeas de Cooperación Territorial ${ }^{4}$. La elección de la fórmula de cooperación suele venir condicionada por las exigencias del Derecho de la Unión Europea, en cuanto, la cooperación que se lleva a cabo en el seno de ésta, permite acogerse a importantes fuentes de financiación, presupuestadas para el logro de los intereses de la Unión en materia de cooperación territorial europea, fundamentalmente fondos FEDER (Fondo Europeo de Desarrollo Regional).

Subrayada la importancia de la cooperación transfronteriza, así como de la utilización de las fórmulas más adecuadas para ello, tenemos que decir que no es el análisis de estas últimas el objeto de este trabajo, cuyo propósito no es atender al marco jurídico europeo de la cooperación transfronteriza, ni en el

\footnotetext{
${ }^{4}$ En lo que hace a las fórmulas organizativas, que permiten la creación de una estructura permanente de cooperación, puede verse el análisis de MARTÍNEZ PÉREZ, E.J. (2010): "El derecho de las entidades locales españolas a participar en los organismos de cooperación transfronteriza”, Anuario Aragonés del Gobierno Local 2009, núm. 1, págs. 233-261.
} 
seno del Consejo de Europa ni en el de la Unión Europea. La finalidad de este trabajo es examinar las normas por las que se rigen las Administraciones Públicas de Andalucía, con el fin de determinar si en dichas normas se atiende o no a la regulación de fórmulas propias de cooperación transfronteriza, más allá de las propias del Derecho europeo. Dicho de otra manera, se trata de ver en qué medida las leyes de las Administraciones Públicas andaluzas contemplan la cooperación transfronteriza, o, no contemplándola, en qué medida casan con el marco jurídico general diseñado por el Derecho europeo, permitiendo la puesta en marcha de técnicas jurídicas de cooperación transfronteriza por nuestras Administraciones Públicas.

Para una adecuada definición del objeto de nuestro estudio, debemos delimitar el mismo, lo que exige llevar a cabo una triple acotación, referida, en un primer término, a los sujetos de la cooperación, en un segundo término, al tipo de cooperación, y, en un tercer término, a la normativa reguladora de la cooperación.

En primer lugar, en lo que hace a los sujetos de la cooperación, tenemos que indicar que cuando nos referimos a las Administraciones Públicas andaluzas nos estamos refiriendo a las que forman parte de la organización territorial de la Comunidad Autónoma de Andalucía, en los términos del art. 89.1 de la Ley Orgánica 2/2007, de 19 de marzo, de reforma del Estatuto de Autonomía para Andalucía (en adelante EAA), en interpretación acorde al art. 137 de la Constitución Española. Por tanto, Administraciones Públicas andaluzas lo son la propia Administración de la Junta de Andalucía, pero también las Administraciones de sus Municipios y Provincias, así como las de las demás entidades territoriales que decidan crearse por ley en el ejercicio de la competencia atribuida a la Comunidad Autónoma por el art. 59 del EAA.

También son Administraciones Públicas andaluzas las entidades instrumentales con personalidad jurídico-pública, esto es, las llamadas Administraciones especializadas o institucionales, que se encuentren adscritas a las anteriores. No obstante, por su naturaleza de entidad instrumental, no territorial, difícilmente puede plantearse la atribución a éstas de la construcción de instrumentos de cooperación transfronteriza, al margen de las entidades territoriales de las que dependen, sin perjuicio de que, en el contexto de su relación con éstas, sí puedan ejercer funciones de cooperación ${ }^{5}$. Lo mismo puede de-

${ }^{5}$ Sobre el concepto de Administración especializada o institucional, véase, entre otros, GAMERO CASADO, E. y FERNÁNDEZ RAMOS, S. (2011): Manual Básico de Derecho Administrativo, $9^{a}$ ed., Tecnos, Madrid, págs. 163 y ss. 
cirse respecto de las entidades jurídico-privadas que conforman el sector público, aunque, en este caso, de ninguna manera pueden considerarse Administraciones Públicas ${ }^{6}$.

En segundo lugar, en lo que hace al tipo de cooperación objeto de este trabajo, lo primero que tenemos que aclarar es que aquí estamos hablando de cooperación territorial, no de cooperación al desarrollo, que es cosa distinta, aunque a veces se desarrolle de forma paralela. A su vez, dentro de los diversos tipos de cooperación territorial posibles, como ya se ha dicho, la que nos interesa es la llamada cooperación transfronteriza, entendiendo por tal aquella modalidad de cooperación territorial que se produce entre entidades públicas limítrofes distintas del Estado. Por tanto, no abordaremos aquí ni la cooperación transnacional ni la cooperación interregional, si bien es cierto que, como se verá, muchas de nuestras conclusiones pueden extenderse también a estos otros dos tipos de cooperación territorial ${ }^{7}$.

La consideración conjunta de esta segunda delimitación junto con la primera, arroja como resultado la conclusión de que la cooperación transfronteriza de las Administraciones Públicas andaluzas se producirá, en todo caso, con entidades públicas pertenecientes a los Estados de Portugal y de Marruecos, por ser éstos los fronterizos con Andalucía, aunque en el segundo caso esté el mar por medio, no siendo más de 14 kilómetros los que separan las costas africanas del Estrecho de Gibraltar ${ }^{8}$.

${ }^{6}$ Acerca del estado actual del sector público andaluz, puede verse el reciente trabajo de FERNÁNDEZ RAMOS, S. (2011): "La reordenación del Sector Público Andaluz. Reflexiones para el debate", Revista Andaluza de Administración Pública, núm. 80, págs. 13-80.

${ }^{7}$ Según BELTRÁN GARCÍA, el principal cometido de la cooperación territorial es "favorecer un desarrollo equilibrado del territorio mediante la cooperación transfronteriza, transnacional e interregional". La primera promueve la colaboración entre entidades limítrofes, la segunda, a partir del establecimiento de grandes zonas, promueve la colaboración entre autoridades nacionales, regionales y locales, mientras que la tercera incentiva, a su vez, las iniciativas entre entidades territoriales. Cfrr. BELTRÁN GARCÍA, S. (2008): "Las Agrupaciones Europeas de Cooperación Territorial (AECT): un instrumento sui generis", en CANALS AMETLLER, D. y GALÁN GALÁN, A. (coord.), Entidades locales y fronteras. Instrumentos jurídicos de cooperación transfronteriza, Fundació Carles Pi i Sunyer d'estudis autonòmics i locals, Barcelona, págs. 89 y 90.

${ }^{8}$ En lo que hace a la cooperación transfronteriza entre Andalucía y las entidades públicas portuguesas, debe destacarse, por ser el instrumento más reciente, la firma del Convenio de Cooperación Transfronteriza para la constitución de la Comunidad de Trabajo "Eurorregión Alentejo-Algarve-Andalucía", suscrito entre la Administración de la Junta de Andalucía, la Comisión de Coordinación y Desarrollo Regional del Alentejo, y la Comisión de Coordinación y Desarrollo Regional del Algarve (publicado en BOJA núm. 134 de 9 de julio de 2010). El marco jurídico previo a este último instrumento ha sido objeto de un completo estudio en FERNÁNDEZ SÁNCHEZ, P.A. (coord.), VV.AA. (2008): La asimetría institucional entre España y Portugal en el marco de la cooperación transfronteriza (Andalucía, Algarve y Alentejo), Atelier, Barcelona. 
En tercer término, hemos de decir que la normativa que se va analizar en este trabajo es la normativa de las Administraciones Públicas andaluzas, no la normativa europea y española en materia de cooperación transfronteriza.

Por tanto, dejamos a un lado el estudio del marco jurídico específico de la cooperación transfronteriza aplicable a Andalucía, que ya ha sido suficientemente estudiado en otros trabajos ${ }^{9}$, y que viene dado, principalmente, por las siguientes normas:

- Convenio-marco europeo de cooperación transfronteriza entre colectividades y autoridades territoriales, adoptado en Madrid el 21 de mayo de 1980, en el seno del Consejo de Europa (BOE núm. 248, de 16 de octubre de 1990), y ratificado por España y Portugal.

- Real Decreto 1317/1997, de 1 de agosto, del Ministerio de Presidencia, sobre comunicación previa a la Administración General del Estado y publicación oficial de los convenios de cooperación transfronteriza de Comunidades Autónomas y entidades locales con entidades territoriales extranjeras (BOE núm. 207, de 29 de agosto de 1997).

- Tratado entre el Reino de España y la República Portuguesa sobre cooperación transfronteriza entre entidades e instancias territoriales, hecho en Valencia el 3 de octubre de 2002 (BOE núm. 219, de 12 de septiembre de 2003).

- Reglamento (CE) núm. 1082/2006, del Parlamento Europeo y del Consejo, de 5 de julio de 2006, sobre la Agrupación Europea de Cooperación Territorial (DOUE L 210 de 31 de julio de 2006).

Por lo que hace a las relaciones entre Andalucía y el Norte de Marruecos, puede verse IGLESIAS, M. (coord.), VALENGIA, A., AGUDO, M., VEGUILLA, V., GUTIÉRREZ, C. (2011): La cooperación transfronteriza Andalucía-Norte de Marruecos, Consejería de la Presidencia, Centro de Estudios Andaluces, Junta de Andalucía, Sevilla.

${ }^{9}$ Acerca del marco jurídico de la cooperación transfronteriza, pueden verse, entre otros, los trabajos de FERNÁNDEZ DE CASADEVANTE ROMANÍ, G. (2008): "Fundamento y marco normativo de la cooperación transfronteriza entre entidades locales", y LÓPEZ RAMÓN, F. (2008): "Régimen jurídico de los acuerdos de cooperación transfronteriza entre entidades territoriales en el marco jurídico promovido por el Consejo de Europa", ambos publicados en CANALS AMETLLER, D. y GALÁN GALÁN, A. (coord.), Entidades locales y fronteras. Instrumentos jurídicos de cooperación transfronteriza, Fundació Carles Pi i Sunyer d'estudis autonòmics i locals, Barcelona. También al respecto, véase HERRERO DE LA FUENTE, A.A. (2007): "La cooperación transfronteriza entre regiones europeas. En busca de un instrumento jurídico eficaz", Revista de Derecho de la Unión Europea, núm. 13, págs. 125-160. 
- Real Decreto 37/2008, de 18 de enero, por el que se adoptan las medidas necesarias para la aplicación efectiva del Reglamento (CE) núm. 1082/2006, del Parlamento Europeo y del Consejo, de 5 de julio de 2006, sobre la Agrupación Europea de Cooperación Territorial (BOE núm. 17, de 19 de enero de 2008).

De esta forma, dado el alcance de este trabajo, no es el marco jurídico propio de la cooperación transfronteriza lo que interesa a nuestro análisis, sino las leyes propias de las Administraciones Públicas andaluzas. Se trata, por tanto, de analizar exclusivamente las principales normas de nuestras Administraciones Públicas, entendiendo por tales aquellas que atienden a su organización, funcionamiento y relaciones, tanto con los ciudadanos como con otras entidades, públicas y privadas, dejando de lado todo el Derecho sectorial. Nuestro propósito es determinar en qué medida este marco normativo se adecua al propio de la cooperación transfronteriza, bien porque incluya previsiones sobre ésta, o bien porque, no incluyéndolas, permita su ejercicio dentro de la letra de la ley.

De esta forma, las normas que tendremos que analizar, como propias de las Administraciones Públicas andaluzas, serán justamente las siguientes:

- Para todas ellas, la Ley Orgánica 2/2007, de 19 de marzo, de reforma del Estatuto de Autonomía para Andalucía.

- Para la Administración autonómica, la Ley 6/2006, de 24 de octubre, del Gobierno de la Comunidad Autónoma de Andalucía, así como la Ley 30/1992, de 26 de noviembre de Régimen Jurídico de las Administraciones Públicas y del Procedimiento Administrativo Común, y la Ley 9/2007, de 22 de octubre, de la Administración de la Junta de Andalucía.

- Para las Administraciones locales, la Ley 7/1985, de 2 de abril, Reguladora de las Bases del Régimen Local, y la Ley 5/2010, de 11 de junio de Autonomía Local de Andalucía.

\section{ANÁLISIS DE LAS LEYES DE LAS ADMINISTRAGIONES PÚBLICAS ANDALUZAS DESDE LA PERSPECTIVA DE LA GOOPERACIÓN TRANSFRONTERIZA}

Puesto que, vamos a analizar tanto las leyes de la Administración autonómica andaluza como las de las Administraciones locales de Andalucía, y tal marco normativo difiere según se trate de una u otras Administraciones Pú- 
blicas, estructuraremos el presente epígrafe en dos apartados, en atención a dicha diferenciación.

\section{Las leyes de la Administración de la Junta de Andalucía.}

En lo que hace a la Ley Orgánica 2/2007, de 19 de marzo, de reforma del Estatuto de Autonomía para Andalucía, ésta atiende específicamente a la cooperación transfronteriza en su art. 246, que lleva por rúbrica, precisamente, "cooperación interregional y transfronteriza". Ahora bien, lo único que hace el precepto es recoger la obligación de la Junta de Andalucía de promover "la formalización de convenios y acuerdos interregionales y transfronterizos con regiones y comunidades vecinas en el marco de lo dispuesto en la Constitución, los Estatutos de Autonomía y la normativa europea de aplicación" ${ }^{10}$.

Sobre este artículo, hay que indicar, en primer lugar, que no hay en él una regulación sustantiva de instrumentos de cooperación transfronteriza, sino tan sólo la escueta referencia a "convenios y acuerdos" de este tipo, reenviando, en realidad, a su regulación específica, con especial atención a la cooperación en el contexto europeo. No obstante, a ello hay que añadir que, el Estatuto de Autonomía no es la norma más adecuada para definir los instrumentos de cooperación, bastando al respecto con lo que hace, que es atribuir a la Junta de Andalucía la obligación de promover esta cooperación.

Por otro lado, debe decirse que no nos convence, por limitada, su ubicación dentro del Capítulo V del Título IX del Estatuto, "Cooperación al desarrollo" ${ }^{11}$, como si la cooperación transfronteriza debiera limitarse a ésta ${ }^{12}$. Sí nos parece acertada su inclusión dentro del Título IX, "Relaciones institucionales de la Comunidad Autónoma".

${ }^{10}$ Vid. ALCAIDE FERNÁNDEZ, J. (2012): “Art. 246. Cooperación interregional y transfronteriza”, en CRUZ VILLALÓN, P. y MEDINA GUERRERO, M. (dir.), PARDO FALCÓN, J. (coord.), Comentarios al Estatuto de Autonomía para Andalucía, Parlamento de Andalucía, Sevilla, págs. 3312-3316.

${ }^{11}$ En FERNÁNDEZ SÁNCHEZ, P.A. (2006): "El nuevo Estatuto de Autonomía de Andalucía y la Acción Exterior", Anuario de Derecho Internacional. XXII, pág. 74, se ha denunciado el caótico enfoque de este capítulo, en el que se mezclan distintos tipos de cooperación. En un sentido similar, véase CARRILLO DONAIRE, J.A. (2008): "La acción exterior de la Junta de Andalucía en el marco internacional extracomunitario", en MUÑOZ MACHADO, S. y REBOLLO PUIG, M. (dir.), Comentarios al Estatuto de Autonomía para Andalucía, Thomson-Civitas, Cizur Menor, págs. 1240 y 1246.

12 Ésta es la interpretación que se hace de dicha ubicación en CARMONA CONTRERAS, A. (2007): "Las relaciones de la Comunidad Autónoma de Andalucía con otros entes públicos", en TEROL BECERRA, M.J. (dir.), La reforma del Estatuto de Autonomía para Andalucía. Las relaciones de la Comunidad Autónoma de Andalucía con otros entes públicos. Pareceres, Instituto Andaluz de Administración Pública, Sevilla, pág. 39. 
Menos específicos, en su conexión con nuestro objeto de estudio, son el art. 239 EAA, que también se refiere a la obligación de promover la cooperación, pero limitada a la cooperación entre las regiones en el seno de la Unión Europea $^{13}$, y el art. 241, que, simplemente, recoge la potestad de la Junta de Andalucía para "suscribir acuerdos de colaboración en el ámbito de sus competencias", "para la promoción de los intereses andaluces", y con el apoyo de "los órganos de representación exterior del Estado"14. Entre estos acuerdos de colaboración pueden situarse, perfectamente, los que suscriba la Comunidad Autónoma con entidades públicas de otros Estados para el ejercicio de la cooperación transfronteriza ${ }^{15}$.

A diferencia del EAA, la Ley 6/2006, de 24 de octubre, del Gobierno de la Comunidad Autónoma de Andalucía, no contiene referencia específica alguna a la cooperación transfronteriza, limitándose a una atribución genérica al Presidente de la Junta de Andalucía, en su condición de supremo representante de la Comunidad Autónoma, de la potestad para "firmar los convenios y acuerdos de cooperación que suscriba la Comunidad Autónoma en los casos que proceda" (art. 7.b), potestad que, por lo demás, es delegable en las personas titulares de las Vicepresidencias y de las Consejerías (art. 11.2.b). Es claro que entre estos convenios pueden incluirse los que tengan por objeto la cooperación transfronteriza, es más, la cooperación territorial de todo tipo, dado el carácter abierto del precepto, que no establece limitación alguna al respecto, y que es por ello coherente con la dicción del EAA.

A esta interpretación coadyuva el hecho de que la Ley también reconozca la proyección de la Presidencia de la Junta de Andalucía en el ámbito inter-

\footnotetext{
${ }^{13}$ A similar conclusión se llega en CARMONA CONTRERAS, A. (2012): “Art. 239. Relaciones con las regiones europeas", en CRUZ VILLALÓN, P. y MEDINA GUERRERO, M. (dir.), PARDO FALCÓN, J. (coord.), Comentarios al Estatuto de Autonomía para Andalucía, Parlamento de Andalucía, Sevilla, pág. 3237, quien critica la redacción del precepto, en el que se contradice su ubicación en el Capítulo dedicado a las "Relaciones con las instituciones de la Unión Europea" con el genérico "regiones europeas" que éste emplea.

${ }^{14}$ La redacción de este precepto ha sido objeto de una importante crítica, por su imprecisión, en FERNÁNDEZ SÁNCHEZ, P.A. (2006): "El nuevo Estatuto de Autonomía de Andalucía y la Acción Exterior", op. cit., págs. 60 y 61 .

${ }^{15}$ En estos términos lo ha entendido ALCAIDE FERNÁNDEZ, J. (2012): "Art. 241. Acuerdos de colaboración”, en CRUZ VILLALÓN, P. y MEDINA GUERRERO, M. (dir.), PARDO FALCÓN, J. (coord.), Comentarios al Estatuto de Autonomía para Andalucía, Parlamento de Andalucía, Sevilla, págs. 3275-3278, quien distingue estos llamados acuerdos exteriores de los tratados internacionales, y los conecta tanto con los acuerdos del art. 6.2 EAA (andaluces en el exterior) como con los del art. 246 EAA (cooperación interregional y transfronteriza).
} 
nacional, representando a la Comunidad Autónoma cuando proceda (art. 7.a ${ }^{16}$. La Ley podría haber sido más explícita al reconocer esta potestad, quizás hubiera sido conveniente, una vez reconocidas las facultades de la Comunidad Autónoma en este ámbito por el EAA, reconocer también expresamente en estos mismos términos dicha facultad al Presidente de la Junta en su Ley de Gobierno. Piénsese que no estamos hablando de un sector material más, sino de la facultad de proyectar de forma transversal la actuación de la Administración autonómica hacia el exterior, en sus relaciones con entidades públicas pertenecientes a otros Estados, y que un reconocimiento expreso proporciona seguridad jurídica. A pesar de todo, pensamos que con la redacción actual es suficiente, no debiendo plantear problema alguno de interpretación.

Por último, debemos analizar la Ley 9/2007, de 22 de octubre, de la Administración de la Junta de Andalucía (en adelante LAJA), que, como ley de la Administración, debiera ser, en su caso, la norma llamada a contemplar mecanismos específicos de cooperación transfronteriza para la Administración Pública andaluza, siempre que no se optara por hacerlo a través de una ley especial, lo que también podría ser una solución, completando lo establecido en el EAA. No obstante, lo cierto es que el examen de la LAJA, revela que no hay en ella una atención especial a esta cuestión, que ha de incardinarse, necesariamente, en la regulación general que se hace de los instrumentos de relación de la Administración andaluza con otras entidades públicas, Capítulo II del Título I de la Ley, que lleva por rúbrica "Instrumentos de colaboración con otras Administraciones Públicas".

Sin embargo, ya desde la propia rúbrica del Capítulo legal citado, puede intuirse lo insuficiente de esta regulación, que no contempla expresamente, y que hace muy difícil encajar en la letra de la Ley, la utilización de instrumentos de cooperación transfronteriza. Ni en el art. 9, que hace referencia a los "convenios de colaboración interadministrativa", ni en el art. 12, que regula la cooperación mediante "organizaciones personificadas de gestión", es posible encontrar una regulación en la que pueda encajarse sin dificultad alguna, la articulación de fórmulas de cooperación transfronteriza. Si bien es cierto que, entre ambos preceptos, el art. 12 admite una interpretación más flexible que el art. 9 .

16 Vid. FERNÁNDEZ ALLÉS, J.J. (2011): "El Gobierno de la Comunidad Autónoma de Andalucía", en FERNÁNDEZ RAMOS, S. y PÉREZ MONGUIÓ, J.M. (coord.), Estudios sobre el Gobierno y la Administración de la funta de Andalucía, Instituto Andaluz de Administración Pública, Sevilla, pág. 32. 
Así, pese a la redacción abierta del precepto, que se limita a reconocer el carácter voluntario de los instrumentos y procedimientos de colaboración, lo cierto es que el art. 9.1 de la LAJA se refiere únicamente a "las relaciones entre la Administración de la Junta de Andalucía y el resto de Administraciones Públicas", entre las que, desde una interpretación algo forzada podríamos incluir a las Administraciones o entidades públicas de otros Estados. En cualquier caso, nada impide a la Administración de la Junta de Andalucía suscribir convenios de colaboración con entidades de Estados extranjeros, puesto que para ello basta con lo dispuesto en los preceptos del EAA y de la Ley del Gobierno de la Comunidad Autónoma, que ya hemos analizado, y con el fundamento que le proporciona estar dotada de personalidad jurídica, (art. 2.2 LAJA), incluyendo la capacidad jurídica que de ésta se deriva. Pero no es eso a lo que nos estamos refiriendo, sino a la ausencia de un reconocimiento expreso de dicha posibilidad en el art.9.1 de la LAJA, siendo así que, hoy por hoy, no sólo no existe este reconocimiento sino que el texto de la misma no encaja como debería con el ejercicio de esta facultad.

Tampoco nos sirve la remisión que el art.9.2 de la LAJA realiza a "la normativa estatal básica sobre régimen jurídico de las Administraciones Públicas", puesto que, lo cierto es que el Título I de la Ley 30/1992, de 26 de noviembre, de Régimen Jurídico de las Administraciones Públicas y del Procedimiento Administrativo Común, que es el que regula las relaciones interadministrativas en dicha Ley, se limita, fundamentalmente, a las relaciones entre la Administración del Estado y la Administración de las Comunidades Autónomas.

Por último, tampoco se ajusta a la cooperación transfronteriza la referencia en este mismo precepto, último párrafo, a la potestad de "la persona titular de cada Consejería en el ámbito de sus competencias", o, en su caso, del Consejo de Gobierno, para aprobar, modificar, o extinguir, los convenios de colaboración. Y es que, como ya hemos dicho, en el caso de la cooperación transfronteriza autonómica, ésta es una potestad atribuida al Presidente de la Junta de Andalucía, sin perjuicio de que pueda delegarla. Por tanto, está claro que lo regulado en el art. 9 de la LAJA es otra cosa.

Sin embargo, en lo que hace al art. 12 de la LAJA, la dicción del precepto sí permite cierta flexibilidad, en la que no sería tan difícil situar a las técnicas de cooperación transfronteriza. Creemos que esto es así porque, cuando el artículo faculta a la Administración de la Junta de Andalucía para constituir "organizaciones personificadas de gestión para la consecución de finalidades de interés común, que pueden adoptar la forma de consorcios o de sociedades mercantiles", indica que éstas se podrán constituir "con otras Administracio- 
nes Públicas y otras entidades públicas o privadas". En nuestra opinión, el carácter abierto de este segundo término de la ecuación, facilita incluir dentro del mismo a entidades públicas pertenecientes a otros Estados.

Más restrictiva es, sin embargo, la acotación que, de los integrantes del ente de cooperación, realiza después el segundo párrafo del art. 12.1, cuando, al remitir al art. 76 de la LAJA para la creación de sociedades mercantiles, dispone que éstas habrán de constituirse "para la prestación de servicios con contenido económico que no impliquen ejercicio de autoridad y que afecten a los intereses de la Administración de la Junta de Andalucía y de otras Administraciones Públicas".

Por otra parte, aunque la LAJA no se refiere expresamente a ellas en este artículo, pensamos que también pueden utilizarse como mecanismo de cooperación las fundaciones del sector público andaluz, reguladas en el art. 78, que remite al régimen establecido por la Ley 10/2005, de 31 de mayo, de Fundaciones de la Comunidad Autónoma de Andalucía. En la medida en que esta Ley permite la constitución de fundaciones por personas jurídicas públicas (art. 8.1), bien pueden tratarse de personas jurídicas públicas pertenecientes a distintos Estados. Los fines de interés general propios de éstas, y algunos de los fines específicamente enunciados en esta Ley (art.3.1), como los "de fortalecimiento institucional, de cooperación para el desarrollo", la "defensa del medio ambiente", o el "establecimiento de vínculos de solidaridad entre las personas y los territorios", se ajustan bien a los propios de la cooperación transfronteriza.

Con todo, en nuestra opinión, la regulación establecida por la LAJA nos sigue pareciendo insuficiente, no sólo porque no regule expresamente los convenios de cooperación transfronteriza, sino porque no se abre a otras posibilidades, como por ejemplo, la creación de organizaciones de gestión no personificadas, esto es, sin personalidad jurídica, por tanto, distintas de los consorcios o de las sociedades mercantiles a las que se refiere el art. 12.

Prueba de esto que estamos diciendo es que el Convenio de Cooperación Transfronteriza para la constitución de la Comunidad de Trabajo "Eurorregión Alentejo-Algarve-Andalucía", firmado entre la Administración de la Junta de Andalucía, la Comisión de Coordinación y Desarrollo Regional del Alentejo, y la Comisión de Coordinación y Desarrollo Regional del Algarve (publicado en BOJA núm. 134 de 9 de julio de 2010), utiliza como fundamento para la publicación del mismo en el BOJA, el art. 12 de la LAJA. Sin embargo, como ya sabemos, este artículo lo que regula son las organizaciones personificadas de gestión, no los convenios de cooperación, ni tampoco las organiza- 
ciones no personificadas, como es el caso de la Comunidad de Trabajo que se crea al hilo de este convenio, pero con fundamento en el art. 10 del Tratado de Valencia.

\section{Las leyes de las Administraciones locales de Andalucía.}

El análisis de la normativa de las Administraciones Públicas locales andaluzas, esto es, Ayuntamientos, Diputaciones Provinciales, y demás entidades locales previstas en la Ley 5/2010, de 11 de junio de Autonomía Local de Andalucía, no arroja resultados muy diferentes a los del estudio del marco normativo de la Administración autonómica, en cuanto a insuficiencia o imprevisión de la regulación de mecanismos de cooperación transfronteriza.

Así, comenzando con el Estatuto de Autonomía para Andalucía de 2007, no puede decirse que en éste exista una atribución directa a las entidades locales andaluzas para llevar a cabo relaciones de cooperación transfronteriza. Todo lo más, dicha posibilidad debe entenderse que es inherente a la "personalidad jurídica propia", y especialmente, a la "plena autonomía en el ámbito de sus intereses", que se reconoce al Municipio en el art. 91.1 del EAA. También, en el mismo sentido, por lo que hace a la Provincia, en atención a la "personalidad jurídica propia" de ésta, en los términos del art. 96.1 del EAA.

No aparece tampoco como una competencia propia de los Municipios, de las recogidas en el art. 92.2 del EAA, y, aunque podría plantearse su encaje en la última letra de éste, ñ), relativa a "las restantes materias que con este carácter sean establecidas por las leyes", pensamos que, no debería ser así, ya que la cooperación transfronteriza no es un sector material de actividad, sino una manifestación de la potestad organizativa de las Administraciones Públicas, en su vertiente relacional, pero hacia el exterior. Por ello, si hay un precepto del EAA en el que directamente pudiera fundarse esta potestad, pensamos que ese sería el art. 91.3, que reconoce la "plena capacidad de autoorganización" de los Municipios, "dentro del marco de las disposiciones generales establecidas por ley en materia de organización y funcionamiento municipal"17.

\footnotetext{
17 Sobre esta regulación, puede verse RIVERO YSERN, J.L. (2008): "El régimen local en el nuevo Estatuto de Autonomía de Andalucía. Reglas sustantivas y distribución de competencias", en MUÑZ MACHADO, S. y REBOLLO PUIG, M. (dir.), Comentarios al Estatuto de Autonomía para Andalucía, Thomson-Civitas, Cizur Menor, págs. 839-866.
} 
Sin embargo, sí puede decirse que se reconoce, aunque sea de forma indirecta, la potestad de las entidades locales andaluzas para emprender relaciones de cooperación transfronteriza, en el art. 247 del EAA, cuando se atribuye a la Junta de Andalucía la función de impulsar y coordinar "las acciones exteriores de las Corporaciones locales, de los organismos autónomos y de otros entes públicos de Andalucía en materia de cooperación exterior, respetando la autonomía que en cada caso corresponda" $"$.

Ahora bien, al margen del EAA, la norma institucional principal de las Administraciones Públicas andaluzas es la Ley 5/2010, de 11 de junio de Autonomía Local de Andalucía (en adelante LAULA). En el análisis de ésta, lo primero que llama la atención es su art. 10, que es el que sigue a la enunciación de las competencias municipales propias del art. 9, y en el que, conectando con todas las fórmulas asociativas a las que nos iremos refiriendo en este epígrafe, se establece que, "para el ejercicio de sus competencias, la prestación de servicios y el desarrollo de iniciativas económicas, los Municipios podrán asociarse entre sí o con otras entidades locales, administraciones públicas o entidades públicas o privadas sin ánimo de lucro, delegar o encomendar el ejercicio de competencias y utilizar cuantas formas de gestión directa o indirecta de servicios permitan las Leyes, sin que en ningún caso se vean afectadas ni la titularidad de las competencias ni las garantías de los ciudadanos". No obstante, esta formulación, que es realmente abierta, y que se adecua bastante bien al enfoque de este trabajo, no se ajusta luego al carácter cerrado de algunas de las determinaciones que iremos exponiendo a continuación.

Es en el Título V de la Ley, bajo la rúbrica de "La cooperación territorial", donde se regulan las relaciones interadministrativas de las entidades locales andaluzas ${ }^{19}$, y, por tanto, donde podría plantearse el encaje de los mecanismos de

${ }^{18}$ Con mayor detalle sobre este precepto, puede verse ALCAIDE FERNÁNDEZ, J. (2012): “Art. 247. Coordinación de acción exterior en materia de cooperación”, en CRUZ VILLALÓN, P. y MEDINA GUERRERO, M. (dir.), PARdO FALCÓN, J. (coord.), Comentarios al Estatuto de Autonomía para Andalucía, Parlamento de Andalucía, Sevilla, págs. 3319-3322. También al respecto, pueden verse los recelos que dicho artículo despierta en FERNÁNDEZ SÁNCHEZ, P.A. (2006): "El nuevo Estatuto de Autonomía de Andalucía y la Acción Exterior", op. cit., pág. 77.

${ }^{19}$ En extenso, sobre esta regulación, véase TOSCANO GIL, F. (2012): "Título V. La cooperación territorial. Entidades e instrumentos para la cooperación territorial: mancomunidades, consorcios, convenios y redes de cooperación”, en RIVERO YSERN, J.L. (dir.), MONTOYA MARTÍN, E. y FERNÁNDEZ RAMOS, S. (coord.), Derecho Local de Andalucía. Ley 5/2010, de 11 de junio de Autonomía Local de Andalucía, Iustel, Madrid, págs. 293-335. También al respecto, puede verse BARRERO RODRÍGUEZ, C. (2010): "Las entidades de cooperación territorial en la Ley 5/2010, de 11 de junio, de autonomía local de Andalucía: Mancomunidades y Consorcios", Nuevas Politicas Públicas. Anuario multidisciplinar para la modernización de las Administraciones Públicas, núm. 6, págs. 59-76. 
cooperación transfronteriza. Aunque, eso sí, debe aclararse que aquí el término "cooperación territorial" no está empleado pensando en la proyección hacia el exterior de las entidades locales andaluzas, no siendo por tanto, coincidente, con el sentido que a tal expresión se le da en la acción exterior, como demuestra el hecho de que el art. 2.2 de la Ley, al definir el objeto de ésta, parta de un enfoque cerrado, limitado a la regulación de las "técnicas de organización y de relación para la cooperación y la colaboración entre las entidades locales y entre estas y la Administración de la Comunidad Autónoma". No obstante, como veremos, ello no nos impedirá defender un enfoque más abierto en alguno de los supuestos regulados.

El Título V de la LAULA se estructura en tres Capítulos bien diferenciados, de los cuales nos interesan los dos primeros. El Capítulo I, rubricado "Fines, principios y tipología de la cooperación", se sitúa a modo de pórtico vertebrador. El Capítulo II contiene la regulación de las "Entidades e instrumentos para la cooperación", dedicando sus Secciones 1. ' y 2. a las Mancomunidades de Municipios y los Consorcios locales, como entidades de cooperación, y su Sección 3. a a los instrumentos de cooperación no organizativos, entre los que se encuentran los convenios y las redes de cooperación.

En lo que hace al Capítulo I, su art. 60, al enumerar los fines de la cooperación territorial, no contiene una referencia expresa a las relaciones con el exterior de las entidades locales andaluzas, pero sí se fija algunos objetivos que encajan perfectamente con ésta, así, por ejemplo, cuando se refiere en el apartado 1, a la finalidad de "propiciar un modelo territorial acorde con los criterios básicos de desarrollo sostenible y de cohesión económica, social y territorial". Pero también, casi cualquiera de los otros fines enumerados en el citado precepto legal.

Por otra parte, el artículo 62 establece la doble tipología a través de la cual se puede articular la cooperación territorial en Andalucía. En dicha disposición legal se distingue claramente entre entidades e instrumentos. Las primeras son técnicas de cooperación organizativas, en cuanto requieren la creación de una nueva organización, dotada de personalidad jurídica. Los segundos son técnicas de cooperación no organizativas, en cuanto no precisan de la creación de una nueva organización dotada de personalidad jurídica. Dentro de las primeras se enumeran las Mancomunidades de Municipios y los Consorcios locales, mientras que entre las segundas se encontrarían los convenios y las redes de cooperación. 
No obstante, tal y como se desprende del propio artículo, este listado no tiene carácter cerrado, por lo que es posible que los sujetos de la cooperación, en el ejercicio de su autonomía, diseñen otras fórmulas distintas de las enumeradas en esta Ley. Así, se permite la creación de cualquier otra modalidad de entidad o de instrumento de cooperación interadministrativa, "que pudiera establecerse para el desempeño de servicios, obras o iniciativas de interés para la cooperación territorial en Andalucía y que se ajuste a los fines y principios de la presente Ley". Esta solución, que nos parece acertada, es en todo caso coherente con la naturaleza de los mecanismos de cooperación interadministrativa en nuestro Derecho ${ }^{20}$, que no responde a un modelo de lista cerrada, sino abierta $^{21}$, y, en el caso del objeto de nuestro estudio, es claro que facilita el encaje de las fórmulas de cooperación territorial transfronteriza en la LAULA. Otra cosa es que dichas fórmulas no se vean reflejadas más que en la posibilidad de utilizarlas y configurarlas en la forma que se estime más conveniente, para lo cual, ciertamente, tampoco hacía falta clausula abierta alguna en esta Ley, bastando con el reconocimiento de la autonomía y la potestad organizativa de las entidades que quieran ejercer tal cooperación.

En lo que hace a las entidades de cooperación reguladas en las Secciones $1^{\text {a }}$ y $2^{\text {a }}$ del Capítulo II de este Título V de la Ley, sólo las segundas, esto es, los Consorcios locales, pueden considerarse mecanismos de cooperación transfronteriza, ya que las primeras, esto es, las Mancomunidades de Municipios, están pensadas únicamente para la asociación de entidades municipales (art. 63.1). Sin embargo, el Consorcio local aparece abierto en la Ley a la integración en el mismo tanto "de entidades locales de distinto nivel territorial", como de "otras administraciones públicas para finalidades de interés común", o "entidades públicas o privadas sin ánimo de lucro, que tengan finalidades de interés público concurrentes" (art. 78.2)22. Entre estas entidades públicas bien puede considerarse la inclusión de entidades públicas pertenecientes a otros Estados.

Esta regulación es coherente con la configuración del Consorcio transfronterizo regulado por la legislación básica estatal, art. 87.2 de la Ley 7/1985, de

\footnotetext{
20 Vid. RIVERO YSERN, J.L. (2002): "La cooperación interadministrativa local", Revista Andaluza de Administración Pública, núm. 46.

${ }^{21}$ Este planteamiento ha sido defendido en CARBALLEIRA RIVERA, M.T. (1993): "La cooperación interadministrativa en la LBRL”, Revista de Estudios de la Administración Local y Autonómica, núm. 257, págs. 57 y 61 .

${ }^{22} \mathrm{Al}$ respecto, véase BARRERO RODRÍGUEZ, C. (2002): "Los conceptos de mancomunidades y consorcios: necesidad de delimitación y diferenciaciones", Revista Andaluza de Administración Pública, núm. 45.
} 
2 de abril, Reguladora de las Bases del Régimen Local, en la redacción dada al mismo por la Ley 57/2003, de 16 de diciembre, de medidas para la modernización del Gobierno local. En dicho precepto se establece que "los consorcios podrán utilizarse para la gestión de los servicios públicos locales, en el marco de los convenios de cooperación transfronteriza en que participen las entidades locales españolas, y de acuerdo con las previsiones de los convenios internacionales ratificados por España en la materia" ${ }^{23}$.

Pasando a los instrumentos de cooperación, Sección $3^{\text {a }}$ del Capítulo II del Título $\mathrm{V}$ de la Ley, debemos decir que la regulación de los convenios de cooperación no resulta satisfactoria desde la perspectiva abordada en este trabajo, por cuanto el régimen jurídico establecido para los mismos, no considera como sujetos de la cooperación a otras entidades que no sean los Municipios, las Provincias, las entidades de cooperación territorial reguladas por esta Ley y la Comunidad Autónoma de Andalucía. Esos son los términos que emplea el art. 83.1 LAULA. Como se comprenderá, se trata de un enfoque demasiado restrictivo, incluso aunque no se estuviera buscando encajar en los preceptos legales la formalización de convenios con entidades públicas de Estados extranjeros, como es el caso.

Entre los instrumentos de cooperación, y como una de las principales novedades contenidas en el Título V de la LAULA, aparecen en su art. 84 las llamadas redes de cooperación territorial, que, en su configuración legal, son una creación de ésta ${ }^{24}$. Si bien, no puede decirse que sean una fórmula nueva en el modelo de cooperación territorial de Andalucía, ya que incluso se encuentran reflejadas en nuestros planes de ordenación del territorio. En el ámbito doctrinal e institucional, esta figura responde a la defensa de las tesis propias de la gobernanza, que propugnan la utilización de técnicas de cooperación multinivel, flexibles, y poco pesadas, que encuentran en las redes de cooperación, uno de sus máximos exponentes ${ }^{25}$.

\footnotetext{
${ }^{23}$ Sobre éste, puede verse NIETO GARRIDO, E. (2008): "El consorcio administrativo como instrumento de cooperación transfronteriza", en CANALS AMETLLER, D. y GALÁN GALÁN, A. (coord.), Entidades locales y fronteras. Instrumentos jurídicos de cooperación transfronteriza, Fundació Carles Pi i Sunyer d'estudis autonòmics i locals, Barcelona, págs. 73-86. También al respecto, vid. MORILLO-VELARDE PÉREZ, J.I. (2011): "Mancomunidades y asociaciones de Municipios", en MUÑOZ MACHADO, S. (dir.), Tratado de Derecho Municipal. Tomo II, Iustel, Madrid, pág. 1612.

${ }^{24}$ Una visión crítica de esta regulación en CARBONELL PORRAS, E. (2011): "La cooperación intermunicipal en la realización de las obras y servicios locales (reflexiones a propósito de algunos mecanismos distintos de la creación de entidades supramunicipales", en VELASCO CABALLERO, F. (dir.), Anuario de Derecho Municipal 2010, Marcial Pons, Instituto de Derecho Local, Madrid, pág. 92.

${ }^{25}$ Pueden verse, entre otros muchos, FERIA TORIBIO, J.M. (dir.), GONZÁLEZ GONZÁLEZ, A. (coord.), RUBIO TENOR, M. y SANTIAGO RAMOS, J. (2007): Redes de cooperación y nuevas formas de go-
} 
La Ley parte de la atribución a las entidades locales andaluzas de la facultad de cooperar a través de dichas redes, y define su ámbito, que puede ser inferior o igual al autonómico, nacional o internacional, situando a las redes de ciudades como el nivel básico y preferente de las redes de cooperación. Este nuevo instrumento de cooperación territorial se concibe en unos términos muy flexibles, lo que se refleja, entre otras cosas, en la propia composición de las redes, que, se dice, pueden estar integradas por personas físicas o jurídicas, públicas o privadas, siempre que persigan fines de interés general local.

Por otra parte, se permite a los miembros de las redes de cooperación territorial la creación de entidades con personalidad jurídica para la gestión de sus intereses. Si bien, en tal caso, estaríamos ya hablando de otra cosa, de una estructura organizativa adicional a la red de cooperación, que debería ajustarse a la normativa que le resulte de aplicación, en función del tipo elegido.

Por todas las características que acabamos de exponer, es claro que la configuración en la LAULA de las redes de cooperación territorial encaja bien con la articulación de mecanismos de cooperación transfronteriza, aunque también es cierto que, posiblemente, encaje aún mejor con los otros tipos de cooperación territorial en el exterior, esto es, la cooperación transnacional y la cooperación interregional.

Dentro de la Sección $3^{a}$, hay que referirse también a la regulación de los órganos paritarios de colaboración entre la Comunidad Autónoma y los Gobiernos locales, en el art. 85 de la Ley, como organizaciones no personificadas. Si bien, lo cierto es que tanto por la limitación legal de los sujetos de la cooperación, que parecen restringirse a los que acabamos de apuntar, como por el carácter deliberante o consultivo de estos órganos, pensamos que esta regulación no aporta nada de interés al tema que nos atañe, que se ve mejor atendido desde la creación de órganos de gestión.

Para finalizar, debemos apuntar que la LAULA, al igual que hacía la LAJA, también contempla la posibilidad de utilizar organizaciones personificadas asociativas de naturaleza jurídico-privada, como las sociedades mercantiles. Si bien, lo cierto es que la sociedad mercantil interlocal regulada en su art. 39 está pensada únicamente para entidades locales, entendemos que, españolas, al

bernanza en Andalucía: una aproximación inicial, Junta de Andalucía, Consejería de Gobernación, Sevilla; y ZAFRA VÍCTOR, M. (2004): "Gobernanza local”, en AAVV, Estrategia regional y gobernanza territorial: la gestión de redes de ciudades, Junta de Andalucía, Consejería de Gobernación, Sevilla. 
no establecerse mayor precisión en dicho precepto legal. Mayor virtualidad podría tener la utilización de fundaciones públicas locales, previstas en los arts. 40-42 de la Ley, que, aunque no puedan considerarse formalmente personificaciones asociativas, sí quedan abiertas a la participación de otras entidades públicas $^{26}$.

\section{CONGLUSIONES}

El análisis en este trabajo de las normas propias de las Administraciones Públicas andaluzas, con el fin de determinar si en éstas se atiende o no a la regulación de fórmulas específicas de cooperación transfronteriza, ha puesto de relieve que ello no es así, que la respuesta a la pregunta que nos hacíamos al principio debe ser en todo caso negativa. Tampoco puede decirse, y ésta era la segunda cuestión que nos planteábamos al principio, que haya una total adecuación entre estas normas y el marco jurídico general de la cooperación transfronteriza, aunque no se pueda hablar de grandes contradicciones. La normativa propia de las Administraciones Públicas andaluzas permite la cooperación transfronteriza, aunque no la atienda de forma específica. Como ha podido verse, desde una cierta flexibilidad en la interpretación de la letra de la ley, a veces algo forzada, puede encajar este tipo de cooperación en la regulación propia de las Administraciones andaluzas.

El panorama legal descrito puede calificarse de insuficiente, puesto que, por supuesto es mejorable. Ahora bien, que dicha insuficiencia sea realmente relevante es, ciertamente, otra cuestión, pues puede que la cooperación transfronteriza se baste con los mecanismos jurídicos establecidos por su regulación específica, principalmente, como es sabido, el Convenio marco del Consejo de Europa, los tratados internacionales firmados al efecto y los reglamentos sobre las Agrupaciones Europeas de Cooperación Territorial.

Es posible también, no lo sabemos, que lo limitado de la casuística existente, la relativa a las relaciones de Andalucía con el Algarve y el Alentejo, y, aho-

${ }^{26}$ Sobre la regulación de estas entidades en la LAULA, véase MONTOYA MARTÍN, E. (2012): "Título II. Los servicios y la iniciativa económica locales", en RIVERO YSERN, J.L. (dir.), MONTOYA MARTÍN, E. y FERNÁNDEZ RAMOS, S. (coord.), Derecho Local de Andalucía. Ley 5/2010, de 11 de junio de Autonomía Local de Andalucia, Iustel, Madrid, págs. 183-190, así como, LÓPEZ GONZÁLEZ, J.I. (2010): "Los servicios locales de interés general y la iniciativa económica local en la Ley 5/2010, de autonomía local de Andalucía", Nuevas Políticas Públicas. Anuario multidisciplinar para la modernización de las Administraciones Públicas, núm. 6, págs. 52-54. 
ra, parece que también con el Norte de Marruecos, permita el establecimiento de soluciones al caso, amparándose en el marco jurídico vigente, y que con ello sea suficiente.

Si ello no es así, y fuera necesario introducir algunos cambios en la regulación actual, bajo la competencia de la Comunidad Autónoma andaluza, esto es algo que tendrán que valorarlo, y decidirlo, los gestores de la cosa pública con responsabilidades políticas en esta materia, y a la vista de la experiencia de los últimos años. Se trata, pues, de una decisión política, que no puede tomarse de espaldas a la realidad, ni con una mera valoración técnica acerca de la letra del texto de una la ley. A nuestro parecer, si dichos cambios se estimaran pertinentes, éstos podrían ir desde la modificación de algunos preceptos de las leyes analizadas en este trabajo, a la aprobación de una ley andaluza de cooperación territorial transfronteriza, también transnacional e interregional, si se quiere, de acción exterior, que, como ley especial, se ocupara de establecer una regulación integral de las distintas técnicas jurídicas de cooperación transfronteriza de las Administraciones públicas andaluzas ${ }^{27}$.

No obstante, en nuestra opinión, si ponemos la mirada en el futuro, debemos tener presente que éste viene marcado por una crisis económica mundial, que no facilitará que Europa dedique grandes recursos a los proyectos de cooperación territorial, sino, más bien, al contrario, que éstos se vean recortados o suprimidos. Desaparecida la financiación, y, por tanto, las iniciativas públicas en esta materia, no tendrían sentido grandes alardes de inventiva en el desarrollo de las técnicas jurídicas.

${ }^{27}$ A no confundir con la vigente Ley 14/2003, de 22 de diciembre, de Cooperación Internacional para el Desarrollo. 